\title{
Traumatic bone cyst of the mandible: A Case Report
}

\author{
Krasimir Chapanov ${ }^{1}$, Stoyan Kazakov ${ }^{1}$, Georgi lliev²
}

1. Department of Department of Oral and Maxillofacial

Surgery, Faculty of Dental Medicine, Medical University, Sofia, Bulgaria.

2. Department of Prosthetic Dental Medicine, Faculty of Dental Medicine, Medical University, Sofia, Bulgaria.

\section{Abstract}

This case report describes the diagnosis and treatment challenges of an accidentally discovered bone lesion in the lower jaw that develops asymptomatically. The X-ray image present an osteolytic heterogeneous single-layer lesion, well sharpened with round borders similar to a group of bone lesions, which include ossifying fibroma, fibrous dysplasia, aneurysmal bone cysts, hemangioma and others. The clinical course and the X-ray finding can make difficult a preliminary diagnosis of the lesion and treatment plan.

Keywords: traumatic bone cyst, noncongenital cyst, pseudocystic lesion

\section{Background}

Traumatic bone cysts are characterized by the presence of an asymptomatic cavity in bone with no epithelial lining. Traumatic bone cysts were first described in 1929 (1). The lesion is mainly diagnosed in young patients most frequently during the second decade of life. They are commonly found in the metaphysis of 
long bones, but are rare in the jaws (2). Traumatic bone cysts are classified as u unilocular, simple, solitary, hemorrhagic, or idiopathic $(3,4,5,6,7)$. They are usually asymptomatic and appear on routine radiographies. Because of the lack of unique clinical and radiographic features, it is important to establish the differential diagnosis between traumatic bone cysts and other bone lesions of the jaws. The definite diagnosis of traumatic cyst is invariably achieved at surgery.

\section{Aim}

The purpose of this clinical case is to present the clinical and radiographic characteristics of traumatic bone cysts and it surgical treatment.

\section{Case presentation}

A 19-years old female patient was admitted to an oral surgery department for consultation and treatment of a bone lesion in the mandible found accidentally on X-ray.

The asymmetry of the patient's face due to laterognathia of the mandible on the right and thickened edge of the mandibular body on the right side were detected. The patient had no history of pain. Normal keratinized and non-keratinized oral mucosa were observed intraorally without any symptoms of infection, prenoplasms, benign or malignant lesions. The patient reported trauma in mental region in childhood.

The radiographic findings were of an osteolytic heterogenic unilocular lesion in the right mental area and at the right body of the mandible under the apexes of the teeth $41,42,43$. The lesion was well defined with round borders with a diameter of $20 \mathrm{~mm}$ surrounded by osteosclerotic area. The lesion was near to the terminal part of the mandibular canal and the mental foramen. The teeth in the lesion borders were vital and periodontal space was normally observed. (Figures 1 and 2)

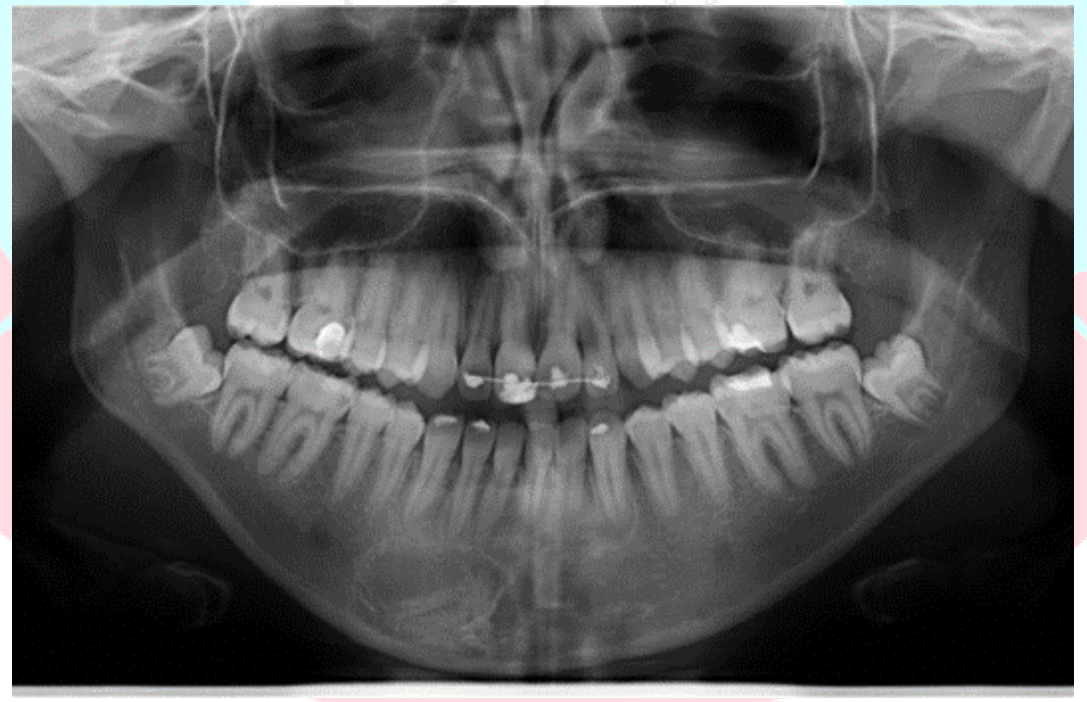

Figure 1: Preoperative panoramic X-ray showing unicystic unilocular and well-defined osteolytic lesion apically from the frontal teeth. 
After analysis of paraclinical data and clinical examination surgical treatment was scheduled. During the surgery the diagnosis of mandibular traumatic bone cyst was confirmed.

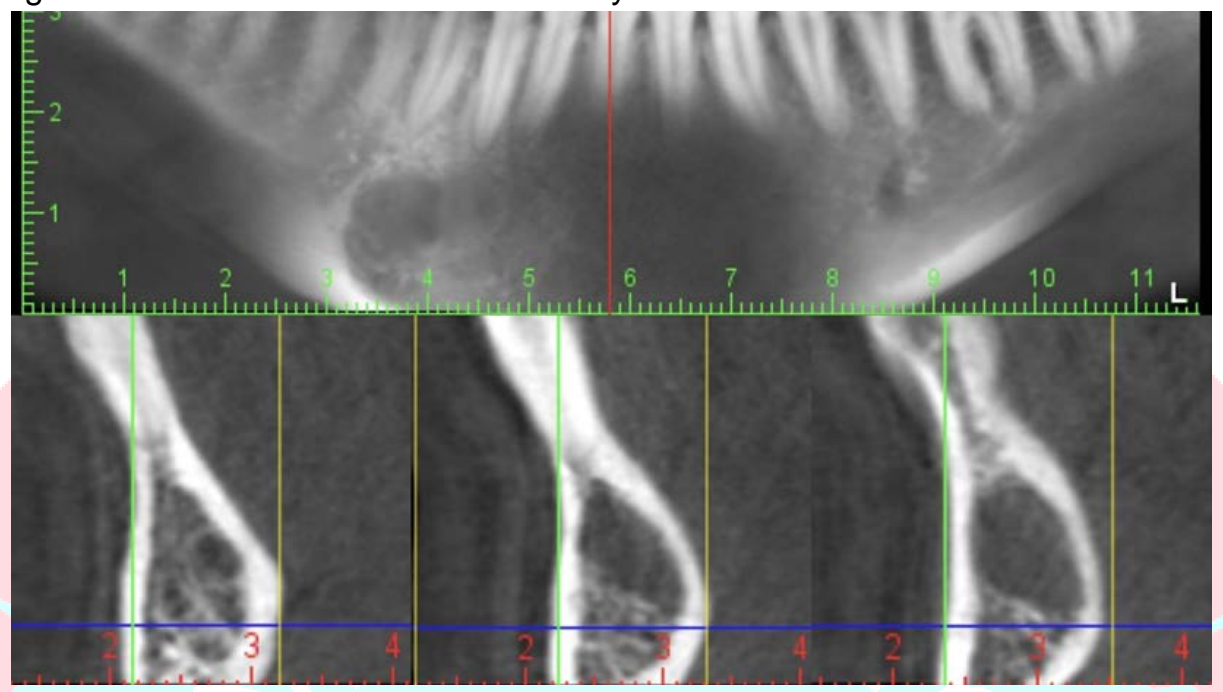

Figure 2. СВСТ before surgery show osteolytic heterogenic unilocular lesion in the right mental area and at the right body of the mandible under the apexes of the teeth $41,42,43$. with a diameter of $20 \mathrm{~mm}$ surrounded by osteosclerotic area.

Intraoperatively, a bone cavity and a pseudocystic lesion filled with serous bloody exudate ware observed. There was no connective tissue or epithelial wall. Therefore, it was difficult histological material to be taken. The walls of the bone lesion were treated by marginal curettage.

The postoperative period was uncomplicated and the patient was followed up. A panoramic X-ray was taken after 4 months (Figure 3), which showed wound healing with a new bone formation.

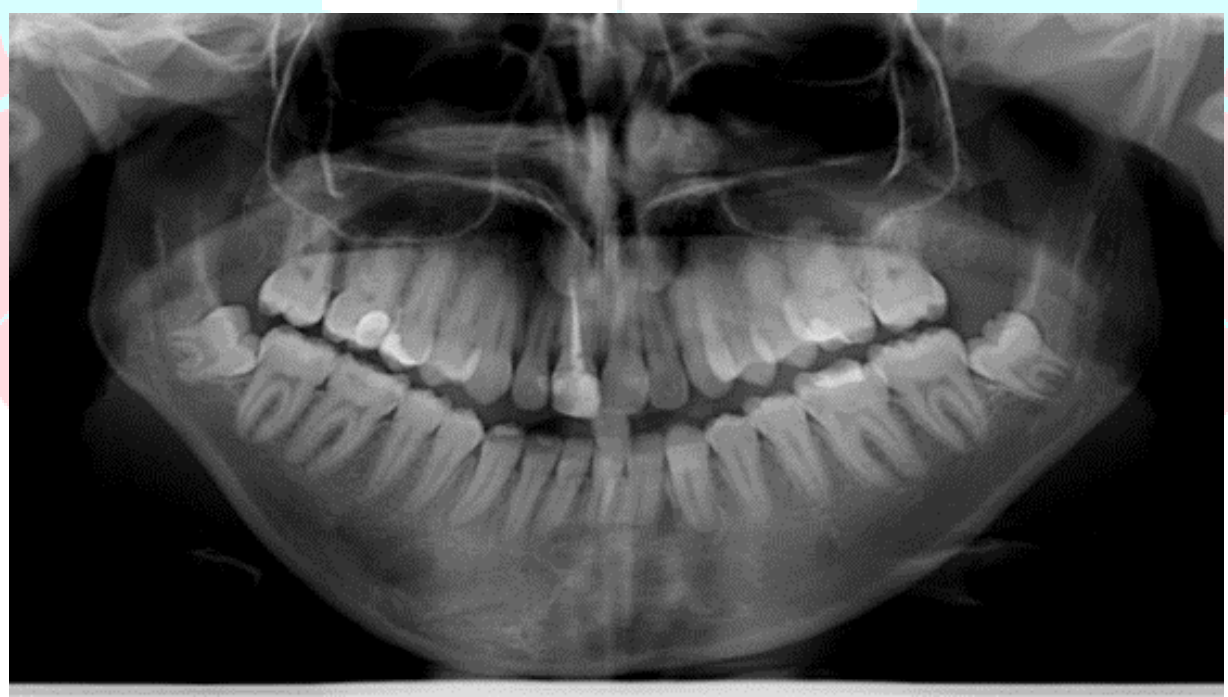

Figure 3: Postoperative panoramic X-ray, four months after surgical treatment. The process of good bone regeneration was detected. 


\section{Discussion}

Traumatic bone cysts are rare lesions of the jaws. They are classified by the World Health Organization (8) as part of a group of similar bone lesions that include the ossifying fibroma, fibrous dysplasia, aneurysmal bone cysts.

Although traumatic bone cysts were described in the beginning of the 20th century, the pathogenesis remains unclear and speculative. It is the most popular the traumatic-hemorrhagic theory, which suggests that lesions develop if intramedullary clots do not undergo lysis or resolution (9). Traumatic bone cysts are more common in young individuals. At a young age, trauma occurs more often. However, reports of trauma at the site of the lesions and the presence of blood in the cavities during the operation are not uncommon, as seen in our sample. This suggests the possibility of the teeth and alveolar processus to participate in the pathogenesis of cysts $(10,11)$. MacDonald-Jankowski $(12)$ has stated that a reduced prevalence of traumatic bone cysts in older patients suggests that this lesion may be self-repairing. Traumatic bone cysts are considered almost exclusively mandibular lesion $(13,14)$. The more common localization in the mandible compared to the maxilla is related to its pathogenesis; the theory of trauma can be explained by the fact that the mandible, which has more cortical bone, recovers at a slower rate than the maxilla.

In most cases, the development of traumatic bone cysts in the maxillofacial area are asymptomatic and do not cause deformation of the cortical bone of the jaw. $(10,12,18,20)$. Traumatic bone cysts usually present as single radiolucent areas in the distal part of the mandible. The border of the lesions can be scalloped $(9,10,11)$. However, this radiographic model can vary considerably - the cyst may be multilocular, associated with teeth connected to the bone lesion. A multiple pattern of traumatic cyst can be observed - there could be more than one traumatic bone cyst in the jaw (17). The differential diagnosis of traumatic bone cyst should be some of the radiolucent lesions such as odontogenic cysts, odontogenic keratocystic, ameloblastoma, odontogenic myxomas, aneurysmal bone cysts, central giant cell lesions and others.

Only a few authors report cases of multiple traumatic bone cysts and their association with fibro-bone lesions - such as cemento-bone dysplasia. $(20,21,22,23)$ Wakasa et al. (23) have suggested that Florid cementobone dysplasia may precede the development of traumatic bone cysts when these two bone conditions are related. This suggests that impaired trabecular formation may interfere with lymphatic drainage and cause traumatic bone cyst formation. Histology of traumatic bone cysts reveals only a connective tissue membrane covering the pathological bone cavity. Cholesterol crystals, hemorrhagic foci and osteoclasts can also be found in the bone lesion. $(23,24)$

A definitive diagnosis of a traumatic bone cyst is almost always confirmed during surgery (as was in our case), and the material available for histology is usually scarce or missing due to the thin and deficient connective tissue wall. Surgeons usually find an empty cavity, although it can be filled with blood, serum, or both. Kuhmichel \& Bouloux (20) noted that such content in the bone cavity may represent different stages in the development of traumatic bone cysts. The treatment of choice for traumatic bone cysts is surgical treatment - curettage of the bone walls $(18,24,25)$. Recurrences are rare after surgery. Cases of multiple cysts or those associated with florid cemento-bone dysplasia have high recurrence rates of about $71 \%$ and $75 \%$, respectively, compared to non-associated bone cyst (26).

\section{Conclusion}

A traumatic bone cyst is an uncommon nonneoplastic lesion of the jaws. It is considered as a "pseudocyst" because of the lack of an epithelial lining. The etiopathogenesis of the lesion remains uncertain but it is often associated with trauma and diagnostic challenges of these asymptomatic lesions should be discussed. 
Radiographic presentation of traumatic bone cyst might have some features in common with other lesions, that it can lead to an inappropriate diagnosis and treatment plan.

\section{References}

1. Lucas CD, Blum T. Do all cysts in the jaws originate from the dental system? J Am Dent Assoc.1929, 16;647-61.

2. Saito $Y$, Hoshina $Y$, Nagamine T, Nakajima T, Suzuki M, Hayashi T. Simple bone cyst. A clinical and histopathologic study of fifteen cases. Oral Surg Oral Med Oral Pathol. 1992, 74;487-91.

3. Wilkins R.M. Unicameral bone cysts. J. Am. Acad. Orthop. Surg. 2000;8(4):217-224.

4. Cataldo E, Santis HR. A clinico-pathologic presentation. The diagnosis is traumatic bone cyst. Journal of the Massachusetts Dental Society. $1995 ; 44(2): 44$.

5. Rushton MA. Solitary bone cysts in the mandible. Br Dent J. 1946, 81;37-49.

6. Harnet JC, Lombardi T, Klewansky P, Rieger J, Tempe MH, Clavert JM. Solitary bone cyst of the jaws: a review of the etiopathogenic hypotheses. J Oral Maxillofac Surg. 2008;66(11):2345-8.

7. Jones AC, Baughman RA. Multiple idiopathic mandibular bone cysts in a patient with osteogenesis imperfecta. Oral Surg Oral Med Oral Pathol 1993, 75;333-340.

8. Barnes L, Eveson JW, Reichart P, Sidransky D. WHO classification of tumours: head and neck tumours. Lyon: IARC Press 2005.

9. Fordyce GL. Haemorrhagic cysts of the mandible. The British Journal of Oral Surgery. 1964 Nov;2(2):8085. DOI: $10.1016 / \mathrm{s} 0007-117 \times(64) 80018-4$.

10. Harnet JC, Lombardi T, Klewansky P, Rieger J, Tempe MH, Clavert JM. Solitary bone cyst of the jaws: a review of the etiopathogenic hypotheses. J Oral Maxillofac Surg. 2008, 66;2345-2353.

11. Posukidis T. Die einfache (traumatische) Knochenzyste der Kiefer [Simple (traumatic) bone cyst of the jaws]. Dtsch Zahnarztl Z. 1982;37(4):365-366.

12. MacDonald-Jankowski DS. Traumatic bone cysts in the jaws of a Hong Kong Chinese population. Clin Radiol 1995, 50;787-878.

13. Seehra J, Horner K, Sloan P. The unusual cyst: solitary bone cyst of the jaws. Dent Update. 2009;36(8):502-508. doi:10.12968/denu.2009.36.8.502

14. Kaugars GE, Cale AE. Traumatic bone cyst. Oral Surg Oral Med Oral Pathol 1987, 63; 318-342.

15. Zehetgruber H, Bittner B, Gruber D, Krepler P, Trieb K, Kotz R, et al. Prevalence of aneurysmal and solitary bone cysts in young patients. Clin Orthop Relat Res 2005, 439; 136-179.

16. Battisti MPL, Soares MQS, Rubira CMF, Bullen IRFR, Lauris JRP, Damante JH. Assessment of spontaneous resolution of idiopathic bone cavity. J Appl Oral Sci. 2018;26:e20170288. doi:10.1590/16787757-2017-0288

17. Tong AC, Ng IO, Yan BS. Variations in clinical presentations of the simple bone cyst: report of cases. J Oral Maxillofac Surg 2003, 61;1487-1578.

18. Hansen LS, Sapone J,Sproat RC Traumatic bone cyst of jaws. Report of sixty-six cases.Oral Surg Oral Med Oral Pathol. 1974; 37:: 899-910

19. Vlcek D, Kuttenberger JJ. Traumatische Zyste des Unterkiefers: von der Entstehung bis zur Therapie. Ein Fallbericht [Traumatic cyst of the mandible. From development to therapy - a case report]. Schweiz Monatsschr Zahnmed. 2013;123(4):319-330.

20. Friedrichsen SW. Long-term progression of a traumatic bone cyst. A case report. Oral Surg Oral Med Oral Pathol. 1993;76(4):421-424. doi:10.1016/0030-4220(93)90006-p 
21. Horner K, Forman GH. Atypical simple bone cysts of the jaws. II: A possible association with benign fibro-osseous (cemental) lesions of the jaws. Clin Radiol 1988, 39;19-63.

22. Miyauchi M, Ogawa I, Takata T, et al. Florid cemento-osseous dysplasia with concomitant simple bone cysts: a case in a Japanese woman. J Oral Pathol Med. 1995;24(6):285-287. doi:10.1111/j.16000714.1995.tb01184.x

23. Wakasa T, Kawai N, Aiga H, Kishi K. Management of florid cemento-osseous dysplasia of the mandible producing solitary bone cyst: report of a case. J Oral Maxillofac Surg 2002, 60; 832-837.

24. Saldaca SA, Gymez PBA, Dhaz CR, et al. Maxillary and mandibular solitary bone cyst. Case report and literature review. Rev Odont Mex. 2018;22(1):40-45.

25. Shigematsu H, Fujita K, Watanabe K. Atypical simple bone cyst of the mandible. A case report. Int J Oral Maxillofac Surg 1994, 23; 298-307.

26. Suei Y, Taguchi A, Tanimoto K. Simple bone cyst of the jaws: evaluation of treatment outcome by review of 132 cases. J Oral Maxillofac Surg 2007, 65; 918-941.

\section{Corresponding author:}

Krasimir Chapanov DMD

Department of Oral and Maxillofacial Surgery,

Faculty of Dental Medicine, Medical University, Sofia

str. St.Georgi Sofiyski 1 1431 Sofia, Bulgaria

Email: kchapanov@gmail.com

Tel: +359885028596 